\title{
Effect of Grinding Treatment of Fly Ash on Compressive Strength of Hardened Geopolymers using Warm Press Method
}

\author{
Shinobu Hashimoto ${ }^{1,},{ }^{*}$, Kosuke Kubota ${ }^{1}$, Kotaro Ando ${ }^{1}$, Yusuke Diko ${ }^{1}$, Sawao Honda ${ }^{1}$, and \\ Yuji Iwamoto $^{1}$ \\ ${ }^{1}$ Nagoya Institute of Technology, Department of Life Science and Applied Chemistry, Gokiso-cho, \\ Showa-ku , 466-8555 Nagoya, JAPAN
}

\begin{abstract}
In this study, starting mixed wet powders were uniaxially compressed at $200 \mathrm{MPa}$ for $40 \mathrm{~min}$ and simultaneously heated at $200{ }^{\circ} \mathrm{C}$ to form hardened bodies. Three different starting slurries composed of $100 \mathrm{~g}$ of fly ash powders with particles of different sizes after grinding treatment, $15 \mathrm{~g}$ of reagent-grade sodium, and $33.3 \mathrm{~g}$ of fresh water were considered. In this time, the uniaxial pressure was fixed at $200 \mathrm{MPa}$. This method is called the warm press method because the heating temperature is not as high as that in the conventional hot press sintering method used for ceramics. When ground fly ash with a diameter of $6.8 \mu \mathrm{m}$ was used, the average compressive strength of the hardened bodies reached approximately $120 \mathrm{MPa}$. As the heating temperature and duration were increased at the fixed uniaxial pressure of $200 \mathrm{MPa}$, the compressive strength of the geopolymers increased. When ground fly ash with a diameter of $6.8 \mu \mathrm{m}$ was used and the heating temperature and duration were $280{ }^{\circ} \mathrm{C}$ and $60 \mathrm{~min}$, respectively, the compressive strength of the geopolymers reached approximately $150 \mathrm{MPa}$.
\end{abstract}

\section{Introduction}

Generally, geopolymer hardened bodies are fabricated by curing a mold of starting slurry consisting of amorphous aluminosilicate, such as fly ash exhausted from a power plant or metakaolin obtained by heating kaolinite clay at approximately $700{ }^{\circ} \mathrm{C}$, and alkali solution [1-3]. Alkali silicate solution is most often added to the starting slurry as a reaction accelerator, but the use of alkali silicate solution is not necessary when geopolymers are fabricated from volcanic ash [4]. Generally, the volume fraction changes easily after the slurry have hardened, causing some cracks to form in the bodies when the curing conditions are not good for the hardening process. To avoid changes in the volume fraction and the formation of cracks inside the hardened bodies, we developed a warm press method in a previous study [5]. In this method, geopolymer starting slurry is first dried at more than

\footnotetext{
*Corresponding author: hashimoto.shinobu@nitech.ac.jp
} 
$100{ }^{\circ} \mathrm{C}$ for several hours to vaporize any water it contains. The resultant hardened sample is ground into particles of less than $500 \mu \mathrm{m}$ in diameter. The particles of the dried sample are placed in a metal mold, and the mold is then set in a warm press device. The mold is uniaxially pressed at $200-300 \mathrm{MPa}$ and simultaneously heated to $300{ }^{\circ} \mathrm{C}$. This method is called the warm press method because the heating temperature is lower than that of conventional ceramic heating using the hot press method. Recently, this warm press method was used to fabricate both geopolymer and calcium hydroxide hardened bodies [6].

So far, the grinding treatment of the starting fly ash has positively influenced the compressive strength of the resultant geopolymers [7-9]. In this study, the effect of the grinding treatment of the starting fly ash on the compressive strength of the resultant geopolymers fabricated using the warm press method was clarified. The relationship between the compressive strength and the relative density of the geopolymer hardened bodies fabricated using the warm press method was examined. Under the warm press conditions of a singular uniaxial pressing at $200 \mathrm{MPa}$, the effect of the heating temperature and duration on the relative density and compressive strength were investigated.

\section{Experimental procedure}

Fly ash exhausted from a Japanese power plant (Chubu Electric Power Co., Inc., Japan) was used as the starting material in this study. The chemical composition of the fly ash is given in Table 1. This is a standard-grade fly ash produced by Japanese coal-fired power generation. The fly ash was ground by a tower mill device (Takahama Industry Co., Ltd., Japan). After tower milling, both the ground power and the fine powder collected by a dust collector were used as the starting coal fly ash material. As a reference, fly ash without tower milling treatment was also used.

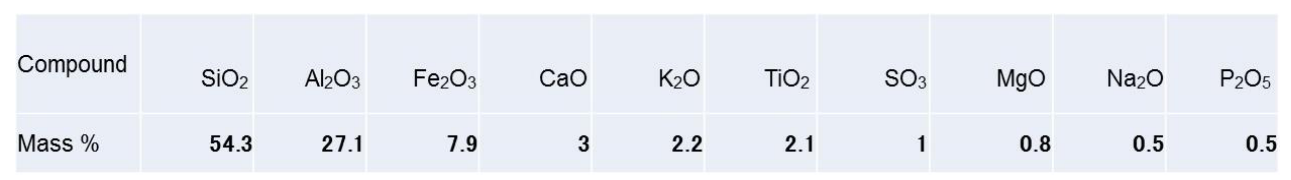

Table 1. Chemical composition of the fly used in this study

For each of the three types of fly ash, $100 \mathrm{~g}$ of fly ash, $15 \mathrm{~g}$ of reagent-grade sodium hydroxide, and $33.3 \mathrm{~g}$ of fresh water were mixed to form starting slurry. The slurry was heated at $130{ }^{\circ} \mathrm{C}$ for $2 \mathrm{~h}$ to vaporize the water. Finally, the dried hardened sample was ground by a conventional mill into particles of less than $500 \mu \mathrm{m}$ in diameter. The obtained particles were placed in a cylindrical steel mold with a diameter of $15 \mathrm{~mm}$, and the mold was set in the warm press device. Beforehand, a thin carbon sheet was used to cover the cylindrical surface of the mold. Fig. 1 shows the warm press device and cylindrical metal mold used in this study. 


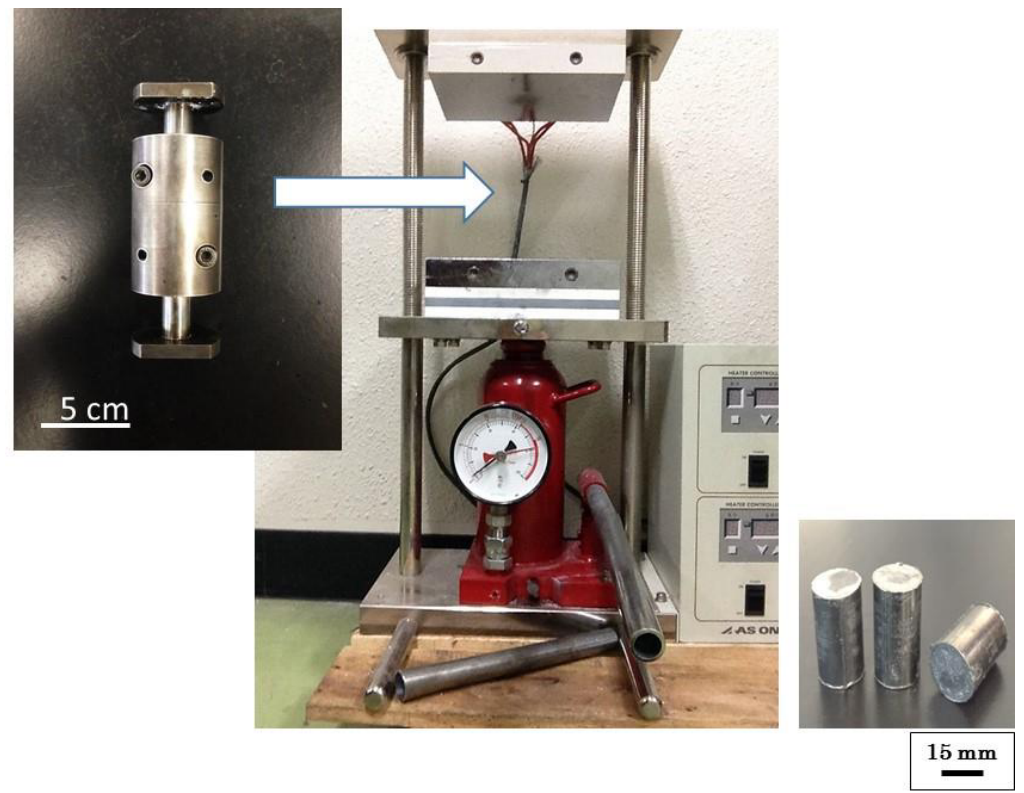

Fig. 1. Photographs of the warm press device, cynlindrical metal mold, and resultant hardened bodies

During the warm press process, temperatures ranged from room temperature to $280{ }^{\circ} \mathrm{C}$ at a constant uniaxial pressure of $200 \mathrm{MPa}$. Starting at room temperature, this fixed uniaxial pressure was applied to the steel mold holding the powder, and the mold was then heated to the desired temperature as measured at the surface of the mold by a contact-type thermocouple sensor. After a fixed molding time, starting from when the mold reached the target temperature, the mold was released from the warm press device, and the hardened sample was removed from the mold. The compressive strength of each of the hardened bodies was determined using an Instron 5582 test apparatus (Instron Co., Ltd., Japan). At least three hardened bodies were used for the compressive strength examination under each set of warm press conditions. The crystal phases of the resultant bodies were analyzed by powder X-ray diffraction (XRD; X'Pert-MPD, Philips). The micromorphology of the sample particles was observed before and after the warm press treatment by scanning electron microscopy (SEM; JMS-6010LA, JEOL). Finally, the concentrations of aluminum and silicon ions eluted into the sodium hydroxide solution were analyzed by inductively coupled plasma mass spectrometry (ICP-MS; ICPS-7000, Shimadzu). During the ICP-MS analysis, $100 \mathrm{~g}$ of distilled water, $5 \mathrm{~g}$ of sodium hydroxide, and $5 \mathrm{~g}$ of fly ash were mixed well while stirring with a rotor for $60 \mathrm{~min}$. After filtration, the remaining water was evaluated.

\section{Results and discussion}

\subsection{Grinding treatment of fly ash}

Fig. 2 shows SEM photographs of the starting fly ash with and without tower milling treatment and their particle size distribution. This figure also shows the fine particles collected by the dust collector. With the grinding treatment, the average size of the fly ash particles decreased from 10.4 to $6.8 \mu \mathrm{m}$, and most particles were not spherical. This fly ash 
was used as the starting material to form the starting slurry for the geopolymer hardened bodies created by warm press.

Fig. 3 shows the variation in the compressive strength and bulk density of the hardened bodies fabricated by warm press (temperature: $200{ }^{\circ} \mathrm{C}$, uniaxial pressure: $200 \mathrm{MPa}$ ) with respect to the average size of the fly ash. When ground fly ash particles with a diameter of $6.8 \mu \mathrm{m}$ were used, the average compressive strength of the hardened bodies reached to approximately $120 \mathrm{MPa}$. When fine spherical fly ash particles gathered by the dust collector were used, the average compressive strength of the

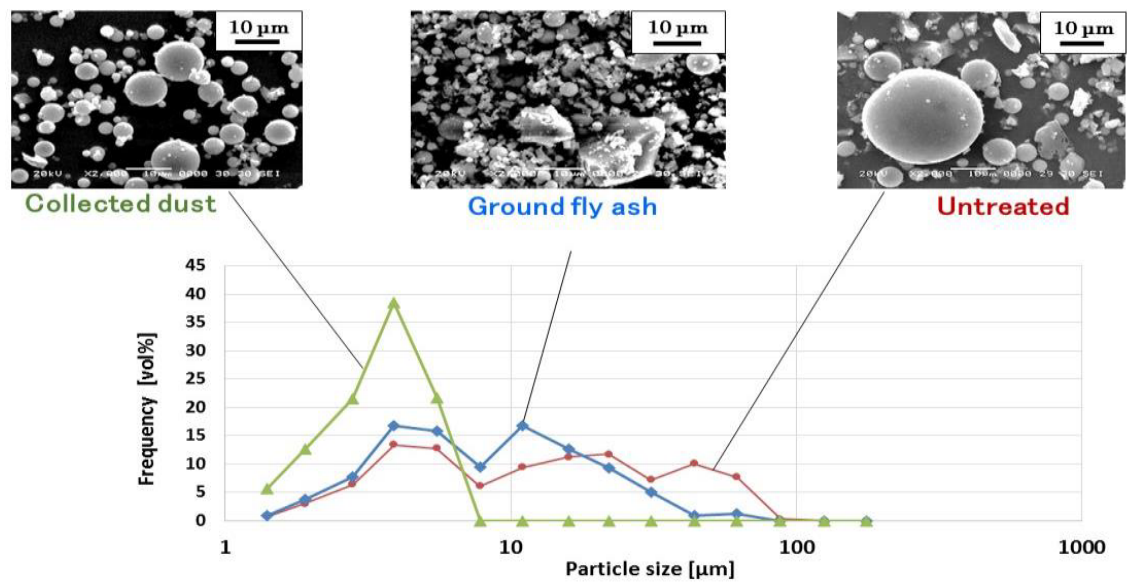

Fig. 2. SEM photographs of the starting fly ash samples with and without tower milling treatment and their particle size distrubutions. As a refecence, data for the original fly ash are also shown

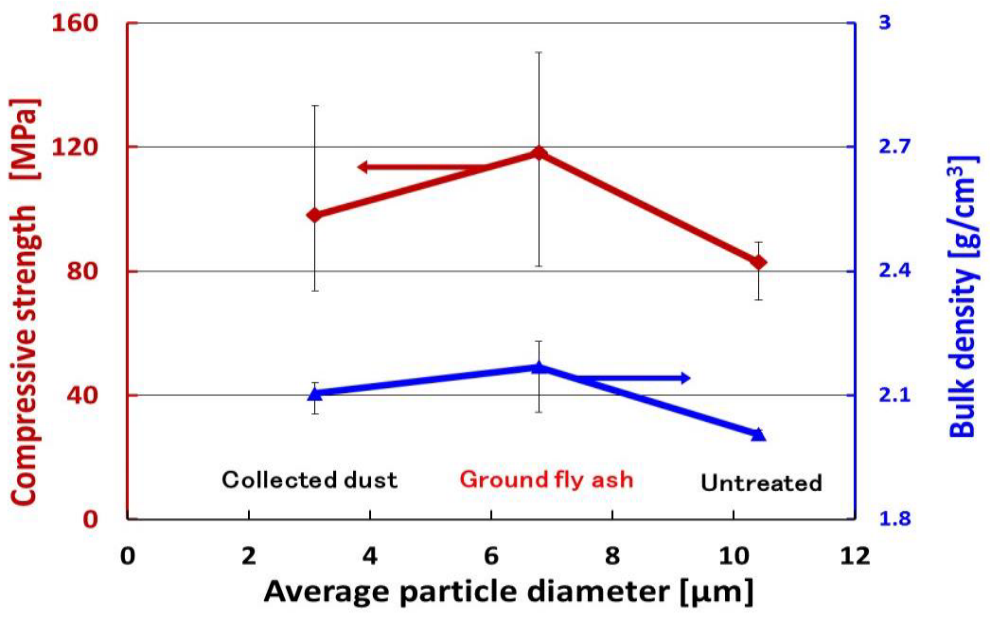

Fig. 3. Compressive strength and bulk density of hardened bodies fabricated by warm press (temperature: $200{ }^{\circ} \mathrm{C}$, uniaxial pressure: $200 \mathrm{MPa}$ ) plotted against the average diameter of the fly ash hardened bodies was approximately $100 \mathrm{MPa}$, which is lower than that of the ground fly ash-derived hardened bodies. Furthermore, after warm press treatment, analysis of magic angle spinning nuclear magnetic resonance (MAS-NMR) spectra confirmed that 
geopolymerization occurred inside the hardened bodies [5]. These results indicate that the grinding treatment of fly ash produces an excellent starting material for geopolymerization.

To clarify the increase mechanism of mechanical strength of geopolymers, the elusion behavior of the three types of fly ash particles in the sodium hydroxide solution was analyzed using ICP-MS. Fig. 4 shows the amount of aluminum and silicon ions eluted from the three types of fly ash immersed in the sodium hydroxide solution. Silicon ions escaped easily from the fly ash particles into the solution. In particular, when the ground fly ash was used, the amount of eluted silicon ions was the largest compared to that for the other types of fly ash, which increased the reaction activity of geopolymerization inside the body. Therefore, the ground fly ash produced the geopolymer products with the largest average compressive strength.

\subsection{Effects of temperature and duration}

Fig. 5 shows the variation in the compressive strength and bulk density of the hardened geopolymer products derived from ground fly ash under a uniaxial pressure of $200 \mathrm{MPa}$ for $40 \mathrm{~min}$ with respect to the heating temperature. The compressive strength of the geopolymer hardened bodies increased with increasing heating temperature. When the heating temperature was $280{ }^{\circ} \mathrm{C}$, the average compressive strength reached approximately $120 \mathrm{MPa}$. However, after heating at $280^{\circ} \mathrm{C}$, the bulk density of the hardened body was the same as that of the body heated at $200^{\circ} \mathrm{C}$. Therefore, as a result, after heating at $200{ }^{\circ} \mathrm{C}$, the compressive strength almost showed the same value.

Fig. 6 shows the variation in the compressive strength and bulk density of the geopolymer hardened bodies under a uniaxial pressure of $200 \mathrm{MPa}$ and a heating temperature of $280{ }^{\circ} \mathrm{C}$ with respect to the heating duration. The average compressive strength increased with increasing heating duration. When the duration was $60 \mathrm{~min}$, the average compressive strength reached approximately $150 \mathrm{MPa}$. In contrast, after $40 \mathrm{~min}$, the bulk density of the hardened geopolymer body was almost the same as that of the hardened body after $60 \mathrm{~min}$. Therefore, if the compressive test sample number increases, the compressive strength remains almost the same.

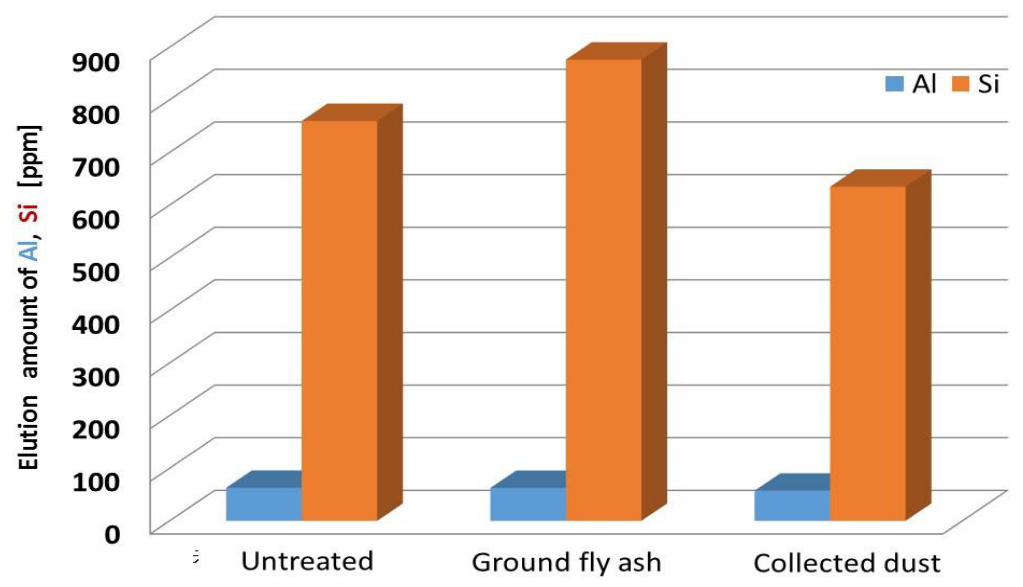

Fig. 4. Amount of aluminum and silicon ions eluted from three types of fly ashes immersed in sodium hydroxide solution 


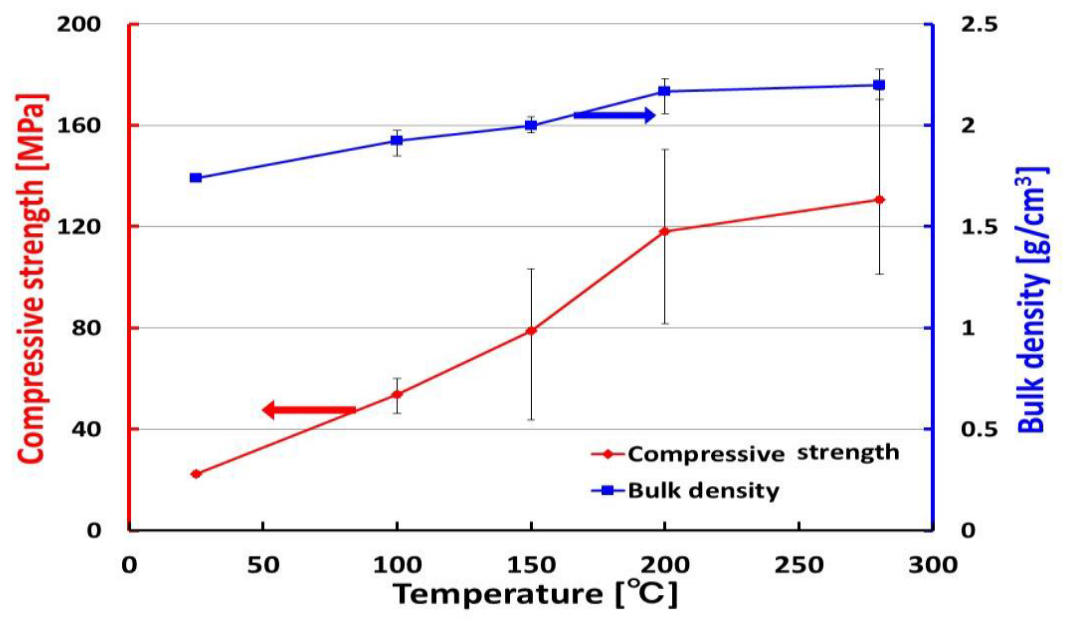

Fig. 5. Compressive strength and bulk density of hardened geopolymer products derived from ground fly ash under a uniaxial pressure of $200 \mathrm{MPa}$ for $40 \mathrm{~min}$ plotted against heating temperature

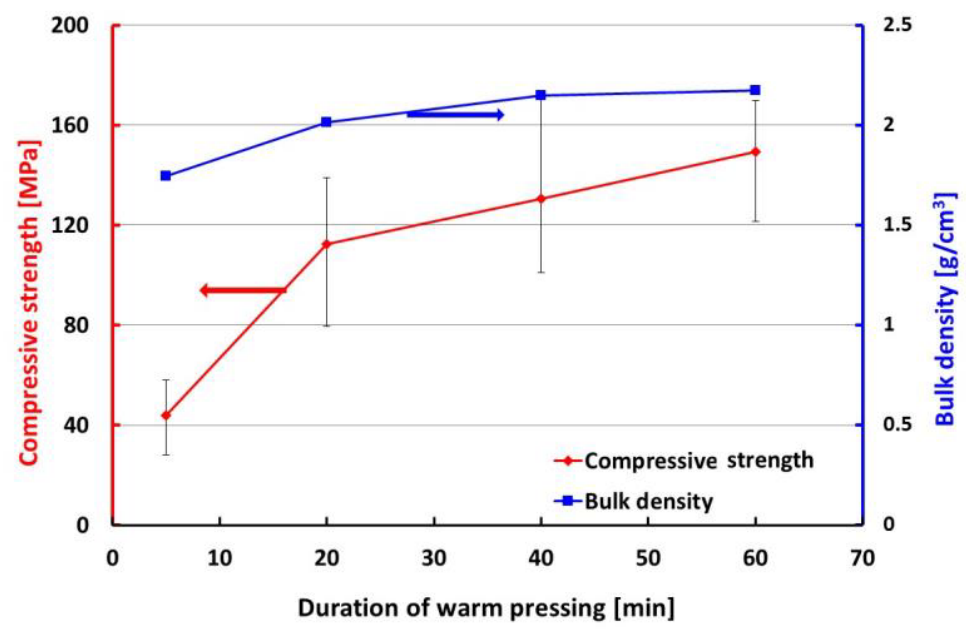

Fig. 6. Compressive strength and bulk density of geopolymer hardened bodies under a uniaxial pressure of $200 \mathrm{MPa}$ and heating at $280{ }^{\circ} \mathrm{C}$ plotted against duration

\subsection{Microstructure of hardened bodies}

Fig. 7 shows SEM photographs of the samples before and after warm pressing at $280{ }^{\circ} \mathrm{C}$ for $60 \mathrm{~min}$. After warm pressing, the microstructure became dense. Uniaxial pressing during heating was thought to decrease the pore volume, leading to the formation of a dense body. Our previous paper discussed the effect of warm pressing on the pores of geopolymer bodies [5]. 


\section{Before}

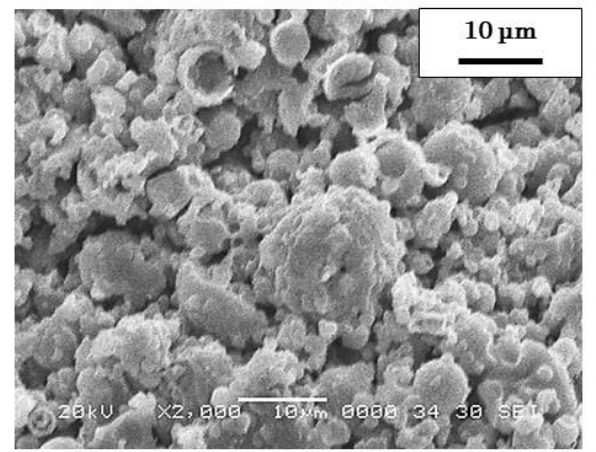

After

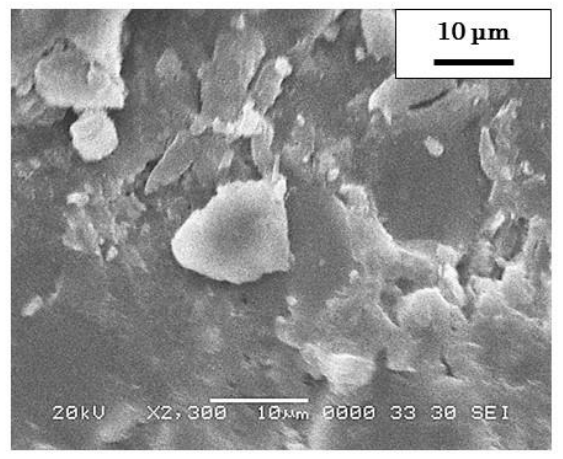

Fig. 7. SEM photographs of samples before and after warm pressing at $280{ }^{\circ} \mathrm{C}$ for $60 \mathrm{~min}$

This warm press method is a very unique and convenient method of fabricating geopolymer products because a geopolymer hardened body can be obtained after only several hours and a sample product with high dimensional accuracy can be fabricated. Furthermore, because the product has a high density and the mechanical strength of the hardened body is very high, this method may be useful as a novel fabrication method of high-performance geopolymer products.

\section{Summary}

Fly ash was ground by a tower mill device into particles with an average diameter of 6.8 $\mu \mathrm{m}$. Fine fly ash powder gathered by a collection filter after grinding was also used as a starting fly ash. As a reference, original fly ash was considered as well. Starting slurries consisting of $100 \mathrm{~g}$ of fly ash, $15 \mathrm{~g}$ of potassium hydroxide, and $33.3 \mathrm{~g}$ of fresh water were dried at $1300{ }^{\circ} \mathrm{C}$ for $2 \mathrm{~h}$. The resultant dried samples were ground into particles with diameters of $500 \mu \mathrm{m}$. Subsequently, a cylindrical steel mold containing the particles was set into a warm press device. When the ground fly ash was used among the three types of fly ash, hardened bodies with the highest compressive strength could be fabricated. When the ground fly ash with an average diameter $6.8 \mu \mathrm{m}$ was used and the heating temperature and duration were $280{ }^{\circ} \mathrm{C}$ and $60 \mathrm{~min}$, respectively, the compressive strength of the geopolymers reached approximately $150 \mathrm{MPa}$.

\section{References}

1. J. Davidovits, J. Therm. Anal., 37, 1633 (1991)

2. H. Takeda, S. Hashimoto, H. Yokoyama, S. Honda, Y. Iwamoto, Materials, 6, 1767 (2013)

3. H. Takeda, S. Hashimoto, T. Iwata, S. Honda, Y. Iwamoto, J. Mater. Cycles Waste., 14, 403 (2012)

4. H. Takeda, S. Hashimoto, H. Kanie, S. Honda, Y. Iwamoto, Ceram. Int., 40, 4071 (2014)

5. H. Takeda, S. Hashimoto, H. Matsui, S. Honda, Y. Iwamoto, Constr. Build. Mater., 50, $82(2014)$ 
6. S. Hashimoto, W. Shimoda, H. Takeda, Y. Daiko, S. Honda and Y. Iwamoto, Constr. Build. Mater., 110, 65 (2016)

7. G. Mucsi, S. Kumar, B. Csoke, R. Kumar, Z. Molnar, A. Racz, F. Madai, A. Debreczeni, Int. J. Miner. Process., 143, 50 (2015)

8. A.M. Mustafa Al Bakri, H. Kamarudin, M. Bnhussain, J. Liyana, C.M. Ruzaidi, Appl. Mech. Mater., 313/14, 169 (2013)

9. G. Mucsi, Z. Molnar, S. Kumar, Acta Phys. Pol. A., 126, 994 (2014) 